\title{
SERVIÇOS
}

O AUTOR

Marco Antônio Guerra

Professor Doutor do Departamento de

Comunicações e Artes da ECA-USP.

\section{BAIRRO DA LUZ: PASSEIO PELA ARTE BRASILEIRA}

$\mathrm{P}$

ara fugir do tradicional esquema de põe os alunos no ônibus e despeja na porta do museu para um passeio com monitores, resolvemos traçar um pequeno roteiro com algumas sugestões para apreciação e entendimento da arte brasileira.

Esta é uma atividade para ser iniciada em classe. Primeiro o professor deverá visitar estes espaços e selecionar o que é necessário e importante ser visto. $\mathrm{O}$ passo seguinte é trabalhar este material em sala de aula.

Para o professor de artes sugerimos que ele proponha trabalhos integrados com a área de História, que dará subsídios para o conhecimento de História do Brasil. Trabalhar com textos pequenos, nos quais se deverá colocar, em linguagem acessível, os conceitos fundamentais do Barroco, do Neoclássico, do Modernismo e da Contemporaneidade.

Deve-se levar em conta a faixa etária dos jovens que farão a visita. Esta é uma atividade adequada para a sétima e oitava séries. Visto que, para crianças menores, é preferí- vel atividades que propiciem participação e atividades plásticas concomitantes. Para a visita de apreciação é necessário um público com maior capacidade de observação.

O segundo momento é ir com o grupo ao local. Esta visita poderá ser feita em ônibus reservado ou de metrô, visto que o ponto de parada inicial é ao lado do metrô Tiradentes e o final, ao lado do metrô da Luz.

O percurso de metrô é interessante por estimular o adolescente a estabelecer relações com o espaço urbano.

A partir deste espaço privilegiado, se poderá traçar uma pequena história da nossa arte, do Barroco ao Contemporâneo. Estamos nos referindo à área do bairro da Luz, onde num espaço de dois quarteirões temos o Barroco, o Neoclássico, os Modernistas e os Contemporâneos.

A visita tem início no Museu de Arte Sacra', onde é importante começar por um estudo do espaço externo. Vale a pena começar pelo exterior, porque o convento da Luz é uma das poucas construções autên-

1. Av. Tiradentes, 676. Bairro da Luz. São Paulo. Telefone: (11) 3326-1373. Site: http://www.uol.com.br/museus/museusp/ sacra.html 
ticas do período colonial que continuam presentes em São Paulo.

$\mathrm{Na}$ transição entre espaço externo e interno, é importante salientar o tipo de construção, chamando a atenção para a largura das paredes, e falando também do processo de caiação que ajuda a proteger as paredes de barro. A presença das cantarias de pedra tem como finalidade reforçar a estrutura das paredes. No interior do Museu temos uma sala com paredes descascadas através das quais são mostradas as três técnicas mais comuns da arquitetura colonial.

O fundamental é o professor fazer o aluno reconhecer as diferentes técnicas ao longo do tempo. Salientar as diferenças entre uma imagem do século XVII e uma do século XVIII. Chamar a atenção para os materiais expressivos das obras: madeira, barro, papier mâché, incluindo aí os metais, a prataria e a ourivesaria.

Pode ser explicado que o colorido das imagens deve-se ao fato da busca do naturalismo que o Barroco pretende. Esculturas possuem olhos de vidro e são devidamente trajadas. Terminando a visita a este espaço interno, é importante não deixar de ver o Presépio Napolitano, datado do século XVIII. Presépio desta qualidade de representação e proporção só existem dois no mundo; este e outro que está exposto no Metropolitan.

\section{DO OUTRO LADO DA RUA: A PINOCOTECA}

Atravessando a rua e dirigindo-se para a esquerda em direção à Estação da Luz, a referência seguinte é a Pinacoteca ${ }^{2}$. No início da visita a este espaço é importante comparar as duas construções no estilo e no material. A arquitetura da Pinacoteca já é identificada por seu autor e aqui é necessário se explicar a produção arquitetônica de Ramos de Azevedo e sua importância nas construções na virada do século XIX/ $\mathrm{XX}$. Originalmente, este projeto era para abrigar o Liceu de Artes e Ofícios, como de fato durante muitos anos ali funcionou, sendo um importante centro de formação de artistas e artesãos especializados.

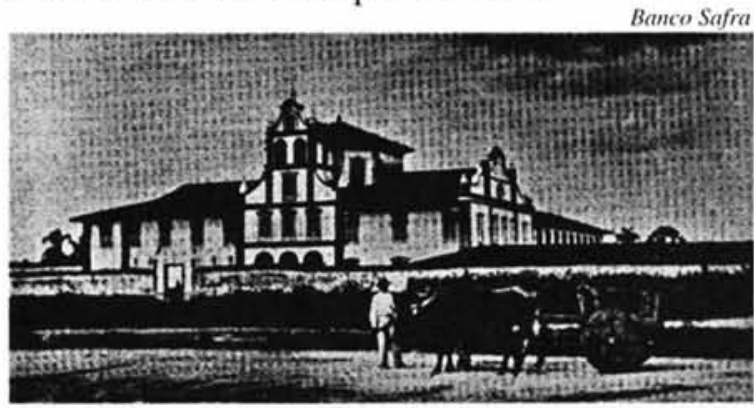

Registro da fachada do Mosteiro da Luz, 1867. que abriga o Museu de Arte Sacra

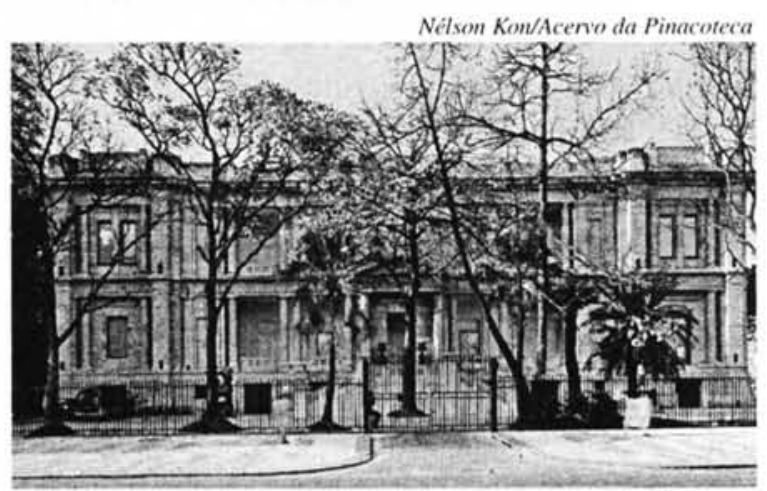

Fachada da Pinacoteca do Estado de S. Paulo, Av. Tiradentes.

Também é importante ressaltar a coerência entre os dois espaços - o da Pinacoteca e o do Museu de Arte Sacra e seus acervos. Estes são identificados com seus espaços abrigos. Ao entrar, é importante esclarecer a arquitetura interna, que foi toda remodelada e cujo projeto respeitou a proposta arquitetônica original, embora tenham sido 
feitas adaptações para que se conseguisse um bom espaço arquitetônico. As intervenções ressaltaram a visualidade do espaço. Neste projeto, do arquiteto Paulo Mendes da Rocha, percebe-se um grande respeito pela memória arquitetônica. É um excelente exemplo de reciclagem de um espaço.

Esta é uma visita cronológica. Visto o Barroco, adentramos um espaço que como o nome sugere é um espaço onde há predominância de quadros.

No Museu de Arte Sacra o predomínio era da escultura; na Pinacoteca a visualidade maior é da pintura. $\mathrm{O}$ professor deverá ter ressaltado a importância dos artistas: Oscar Pereira da Silva, Benedito Calixto, Almeida Jr., Pedro Alexandrino, Eliseu Visconti, Rodolfo Amoedo, Arthur T. da Costa, entre outros. Nessas pinturas é importante se observar a tentativa de fixação de uma arte brasileira, principalmente quanto aos temas; o esforço por uma linguagem nacionalista, o que vai se concretizando no segundo andar, dedicado aos modernistas: Anita Malfatti, Tarsila do Amaral, Lasar Segall e significativas obras de Victor Brecheret.

Resumo: $\mathrm{O}$ autor propōe um roteiro pelas artes a partir de visita ao Bairro Luz, espaço que abriga monumentos e museus de grande importância para a arte brasileira. Do Barroco à arte Contemporânea o professor poderá proporcionar aos alunos, de sétima e oitavas séries, uma boa idéia da riqueza das produçōes artísticas. O passeio propõe a visita ao Museu de Arte Sacra, à Pinoteca do Estado e ao Parque da Luz, hoje totalmente restaurado.

Palavras-chave: arte brasileira, roteiro artístico, Museu de Arte Sacra, Pinacoteca, Parque da Luz

\section{Neste percurso o aluno}

consegue referencial para entender como se formou a Arte Moderna brasileira.

É hora de o professor explicar sobre a Semana de Arte de 22. É hora de se retomar o assunto já iniciado em sala de aula e que, para melhor aproveitamento, deve ter contado com o apoio do professor de Português e/ou de Literatura.

Intervalo, porque ninguém é de ferro a cafeteria da Pinacoteca é ótima.

Retomando a atividade, uma volta pelo Parque da Luz é imperdível (foi restaurado e tornou-se transitável). Ele data do século XIX e era o Jardim Botânico da cidade. Possui um belo acervo de lagos e esculturas clássicas junto de esculturas contemporâneas que se integram à vegetação.

Com este passeio final, a visita se concretiza unindo a arte Clássica à Contemporânea.

(The Luz District: in the name of Brazilian art) Abstract. The author proposes a route through the arts, starting with a visit to the Luz District, a place that houses many monuments and museums of great importance for Brazilian art. From Baroque to Contemporaneous art, teachers may give their seventh and eighth grade students a good idea about the richness there is in the artistic productions. The itinerary proposes a visit to the Museu de Arte Sacra (Religious Art Museum), to the Pinoteca do Estado (State Art Museum) and to the Parque da Luz (Luz Park), which has been totally restructured.

Key words: Brazilian art, artistic route, Museu de Arte Sacra (Religious Art Museum), Pinoteca do Estado (State Art Museum), Parque da Luz (Luz Park) 